\title{
Validation and optimization of cutting parameters for Ti-6Al-4V turning operation using DEFORM 3D simulations and Taguchi method
}

\author{
Japheth Oirere Obiko ${ }^{1,2}$, Fredrick Madaraka Mwema ${ }^{3,4}$, and Michael Oluwatosin Bodunrin ${ }^{2,5, *}$ \\ ${ }^{1}$ Department of Mining, Materials and Petroleum Engineering, Jomo Kenyatta Universityof Agricculture and Technology, \\ Nairobi, Kenya \\ 2 School of Chemical and Metallurgical Engineering, University of the Witwtaresrand, Johanesburg, South Africa \\ 3 Deaprtment of Mechanical Engineering Science, University of Johannesburg, South Africa \\ 4 Materials, Design \& Manufacturing Group (MADEM), Department of Mechanical Engineering, Dedan Kimathi University \\ of Technology, Nyeri, 10143, Kenya \\ 5 African Academy of Sciences, PO Box 24916-0052, Nairob, Kenya
}

Received: 26 September 2020 / Accepted: 13 January 2021

\begin{abstract}
In this study, we show that optimising cutting forces as a machining response gave the most favourable conditions for turning of Ti-6Al-4V alloy. Using a combination of computational methods involving DEFORM simulations, Taguchi Design of Experiment (DOE) and analysis of variance (ANOVA), it was possible to minimise typical machining response such as the cutting force, cutting power and chip-tool interface temperature. The turning parameters that were varied in this study include cutting speed, depth of cut and feed rate. The optimum turning parameter combinations that would minimise the machining responses were established by using the "smaller the better" criterion and selecting the highest value of Signal to Noise Ratio. Confirmatory simulation revealed that using cutting speed of $120 \mathrm{~m} / \mathrm{min}, 0.25 \mathrm{~mm}$ depth of cut and $0.1 \mathrm{~mm} / \mathrm{rev}$ feed rate, the lowest cutting force of $88.21 \mathrm{~N}$ and chip-tool interface temperature of $387.24{ }^{\circ} \mathrm{C}$ can be obtained. Regression analysis indicated that the highest correlation coefficient of 0.97 was obtained between cutting forces and the turning parameters. The relationship between cutting forces and the turning parameters was linear since first-order regression model was sufficient.
\end{abstract}

Keywords: Ti-6Al-4V machining / cutting forces / finite element analysis / ANOVA / regression

\section{Introduction}

Ti-6Al-4V, an $\alpha+\beta$ titanium alloy remains the most studied and most utilised titanium alloy. It is amenable to different heat treatments or thermomechanical treatments which do not only manipulate its phase constituents but yield a good combination of mechanical properties [1-3]. The balanced combination of corrosion resistance, biocompatibility and mechanical properties exhibited by this alloy makes it potentially attractive for a wide range of applications $[4,5]$. As one of the foremost titanium alloys developed in the 1950s, the alloy is used widely for making aerospace and military components, however, its applicability spans through other industries such as chemical, jewellery, automotive and biomedical industries [6].

\footnotetext{
* e-email: mobodunrin@gmail.com; michael.bodunrin@wits .ac.za
}

Ti-6Al-4V alloy, like many other titanium alloys, is only used where its attractive properties outweigh the cost of the alloy [7]. For example, aluminium alloys and aluminium based composites are preferred lightweight materials to titanium alloys in the automotive industry because of their affordability $[8,9]$. Hence, high cost has been the main impediment to the widespread use of titanium alloys [9]. The high cost of production of titanium alloys is due to several factors including difficult extraction process due to affinity for interstitial elements, use of expensive alloying elements such as vanadium, molybdenum, niobium and tantalum, multi-stage forging involving up to forty steps and difficult machining $[2,10]$. Of these factors, machining has been reported to be the most significant as it accounts for $40 \%$ of the total cost of making finished titanium components and up to $90 \%$ loss of material is incurred during the process [7,11]. The difficulty in machining titanium is due to low elastic modulus, low thermal conductivity and alloy composition [12]. Several 


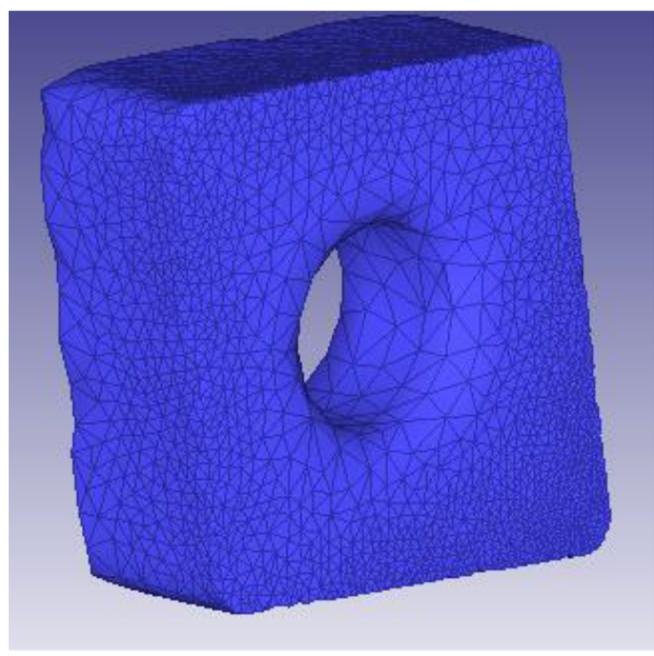

(a)

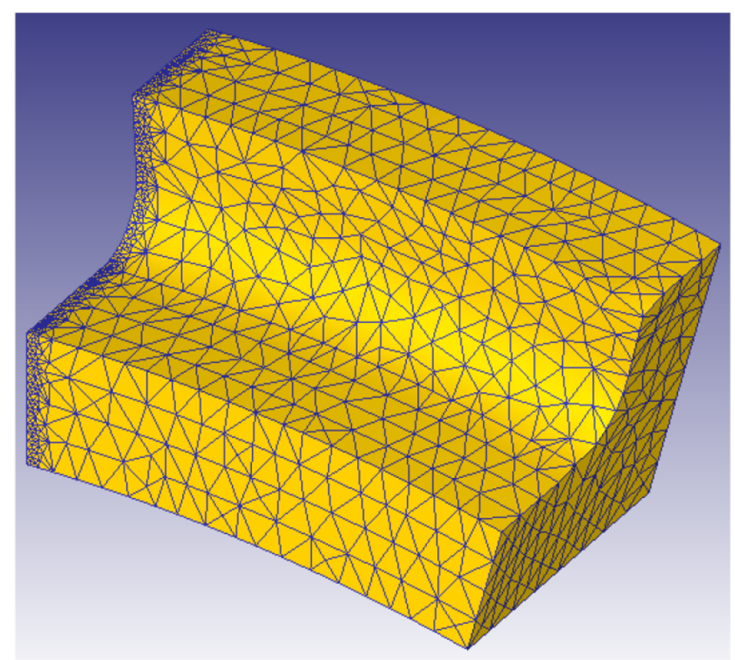

(b)

Fig. 1. Meshed WC tool and Ti-6Al-4V workpiece.

Table 1. Turning parameters for the simulation model Genga et al., [45].

\begin{tabular}{lllll}
\hline Parameters & \multicolumn{4}{c}{ Values } \\
\hline Cutting speed $(\mathrm{m} / \mathrm{min})$ & 30 & 60 & 120 & 150 \\
Depth of cut $(\mathrm{mm})$ & 0.25 & 0.75 & 1.00 & 2.00 \\
Feed rate $(\mathrm{mm} / \mathrm{rev})$ & 0.30 & 0.25 & 0.15 & 0.100 \\
\hline
\end{tabular}

approaches have been adopted to reduce the contribution of machining to the cost of manufacturing titanium alloys, some researchers have developed novel powder metallurgy routes $[13,14]$ such as the FAST forge $[15,16]$ which allows for direct production of near-net-shaped components with little or no machining while others have focused on improving machinability of titanium alloys through parametric optimisation methods [17-20].

There has been a remarkable success in developing novel processes which neglect machining during processing of titanium components, but the translation of these processes to full-blown technology for large-scale commercial production is still at the infant stage [7,21]. Consequently, research efforts which focus on the optimisation of the various parameters for the conventional machining processes have continued to be of interest to researchers. These parameters largely depend on whether traditional machining such as milling, drilling and turning [22-24] are used, or non-traditional methods such as electrochemical machining [25], electrical discharge machining [26], laser beam machining and ultrasonic machining [27] are utilised.

In most cases, studies involving full factorial experimental design $[20,28]$ have been used to optimise parameters for machining of Ti- $6 \mathrm{Al}-4 \mathrm{~V}$ and other titanium alloys. For instance, in the traditional machining where there is contact between the cutting tool and the titanium workpiece, many process parameters are involved. These include cutting tool material, geometry of the cutting tool, lubrication conditions, tool life, cutting speed, depth of cut, feed rate, cutting power, cutting forces, chip formation, tool-chip interface temperature and surface roughness $[29,30]$. Understanding the relationship between these parameters and how they influence the machinability of titanium alloys require high experimental cost. Therefore, computational methods involving finite element simulations, Taguchi method, Artificial Neural Networks have become more attractive to researchers since these methods have the potential of reducing the cost of experiments significantly [20,31-33].

In this study, a validated DEFORM 3D finite element simulation, Taguchi DOE, and ANOVA analyses were used to evaluate the influence of cutting parameters such as depth of cut, cutting speed and feed rate on common machining responses: cutting forces, chip-tool interface temperature and cutting power during turning of Ti- $6 \mathrm{~A}-4 \mathrm{~V}$ alloy. Since it is well established that lower cutting forces and lower chip-tool interface temperature often results in good machinability [34], the main objective in this study was to determine the most effective machining response to be optimised to obtain lower cutting force and chip-tool interface temperature (Tab. 1).

\section{Methods}

\subsection{Finite element simulation on DEFORM 3D}

Finite element analysis (FEA) has been used widely in many production processes, such as forging and machining [35-38]. The application of FEA in the production industry saves time and production cost, hence reducing the tedious design process $[39,40]$. Researchers have used finite element method to predict the effect of machining parameters (cutting speed, depth of cut, tool geometry and feed rate) on the cutting forces, chip formation, temperature, stress and pressure distributions [41,42]. The results obtained from FEA have shown to be comparable with experimental results $[43,44]$. 


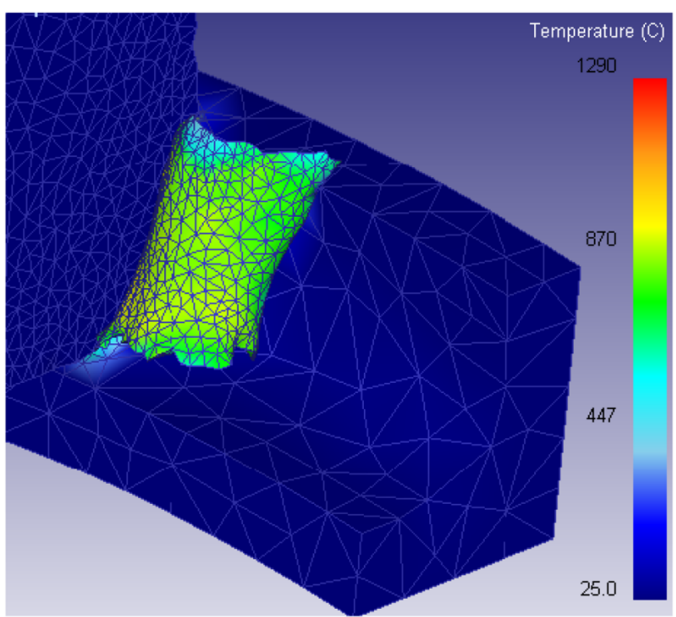

(a)

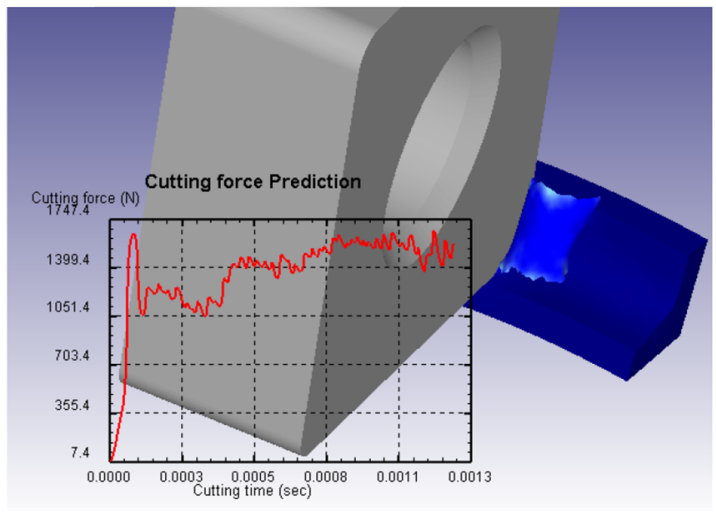

(c)

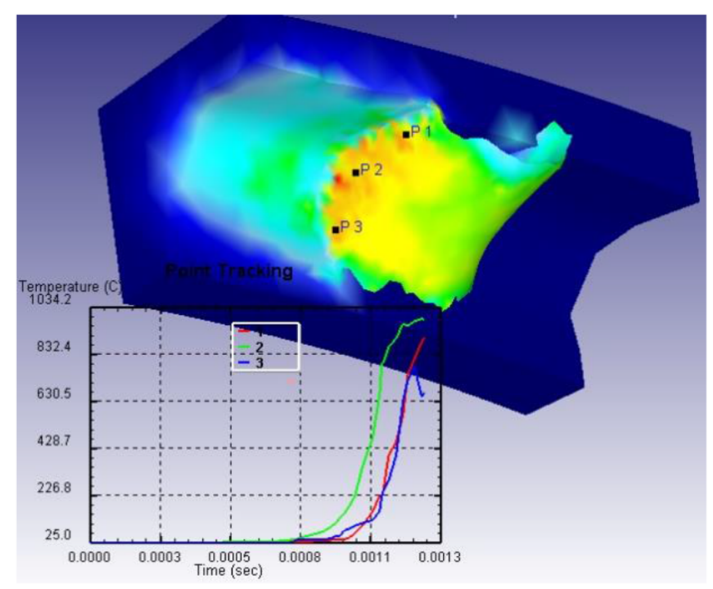

(b)

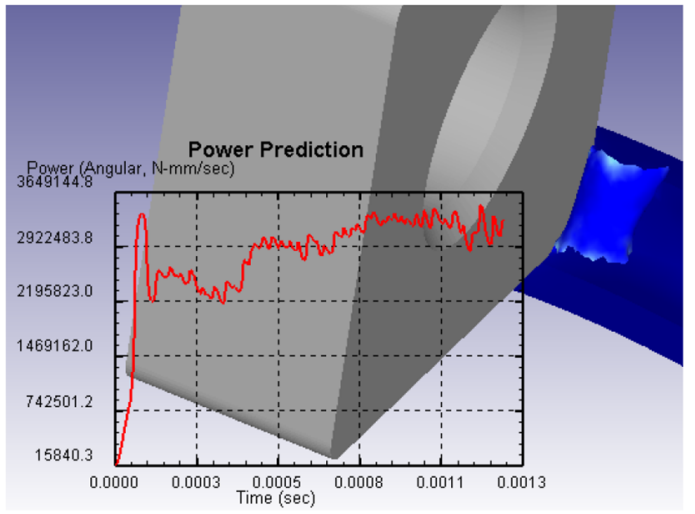

(d)

Fig. 2. Representative illustration of the DEFORM simulation at $120 \mathrm{~m} / \mathrm{min}$ cutting speed, $2 \mathrm{~mm}$ depth of cut and $0.15 \mathrm{rev} / \mathrm{min}$ feed rate showing (a) temperature distribution (b) point tracking of temperature at the chip-tool interface (c) cutting force prediction and (d) cutting power prediction.

In this study, DEFORM 3D ${ }^{\circledR}$ v11.0 software has been used to study orthogonal turning of Ti- $6 \mathrm{Al}-4 \mathrm{~V}$ alloy shown in Figure 1a. The cutting tool (DNMA432) and tool holder (DCKNR) used in this study are from the software library. Geometric parameters of the tool and tool holder were as per default software geometrical dimensions. The material studied (Ti-6Al-4V alloy) was taken from the software library Figure 1b. The turning simulation parameters are as given in Table 1 were selected based on an experimental study conducted by Genga et al. [45]. Genga et al. [45] considered cutting speed of 60 and $120 \mathrm{~m} / \mathrm{mm}, 0.75$ and $1.0 \mathrm{~mm}$ depth of cut and 0.25 and $0.15(\mathrm{~mm} / \mathrm{rev})$ feed rate in their work. In this work, additional parameters were added to expand the experimental matrix. The turning parameters considered in this study are as shown in Table 1. On the DEFORM machining module, the selected workpiece had a curved configuration with a diameter of $50 \mathrm{~mm}$. Only a segment $\left(25^{\circ}\right)$ of the workpiece was modelled to reduce the number of elements, thus reducing the computational time. The workpiece was modelled as a plastic object. The meshed workpiece had tetrahedron elements generated using the automatic software mesh generation system. This implies that re-meshing was set within the system using incremental Lagrangian formula-
Table 2. Turning simulation model conditions.

\begin{tabular}{ll}
\hline Input parameters & Values \\
\hline Workpiece temperature & 25 \\
Tool temperature $\left({ }^{\circ} \mathrm{C}\right)$ & 25 \\
Environment temperature $\left({ }^{\circ} \mathrm{C}\right)$ & 25 \\
Friction factor & 0.6 \\
Convection coefficient between & 0.02 \\
tool and environment $\left(\mathrm{N} / \mathrm{s} \mathrm{mm}{ }^{\circ} \mathrm{C}\right)$ & 45 \\
Heat transfer coefficient $\left(\mathrm{N} / \mathrm{s} \mathrm{mm}{ }^{\circ} \mathrm{C}\right)$ & \\
\hline
\end{tabular}

tion during the simulation. The minimum element size, for the workpiece, was specified at $25 \%$ of the feed rate. Tungsten carbide which was used by Genga et al. [45] in their experiment was selected as the tool material in DEFORM. You et al. [46] reported that carbide tools are the best tool for turning titanium alloys. The cutting tooltip and the cutting zone in the workpiece had a finer mesh density to increase the simulation output accuracy. Figure 2 shows representative images of the machining 
Table 3. Simulation control factors and levels.

\begin{tabular}{lllllll}
\hline Factors & \multirow{2}{*}{ Units } & Symbol & \multicolumn{4}{c}{ Levels } \\
\cline { 3 - 7 } & & & 1 & 2 & 3 & 4 \\
\hline Cutting speed & $\mathrm{m} / \mathrm{min}$ & $\mathrm{Cs}$ & 30 & 60 & 120 & 150 \\
Depth of cut & $\mathrm{mm}$ & $\mathrm{Dc}$ & 0.25 & 0.75 & 1.00 & 2.00 \\
Feed rate & $\mathrm{mm} / \mathrm{rev}$ & $\mathrm{Fr}$ & 0.10 & 0.15 & 0.25 & 0.30 \\
\hline
\end{tabular}

simulations on DEFORM. The cutting tool was considered as a rigid object and moved at a specified cutting speed by using 25000 tetrahedron elements. During turning, shear friction occurs between the chip and the rake face of the cutting tool [47]. In 3D machining simulation, shear friction between the cutting tool and the workpiece was taken to be constant with friction factor of 0.6 representing a wet machining condition. The finite element simulation conditions used in this study are summarised in Table 3.

The cutting forces generated as the tool moves over the surface of the workpiece in orthogonal turning are obtained in the $\mathrm{x}, \mathrm{y}$ and z-directions as $F_{x}, F_{y}$ and $F_{z}$ respectively. The resultant force in this study was calculated using equation (1) [48]:

$$
F=\sqrt{\left(F_{x}\right)^{2}+\left(F_{y}\right)^{2}+\left(F_{z}\right)^{2}}
$$

\subsection{Taguchi methodology}

Taguchi's design approach is a statistical tool that provides means of simultaneously studying the effect of multiple variables. This method provides an easier way to understand the relationship between parameters in a given production process. In this technique, a set of parameters can be studied to optimise the production process, hence improving the quality of the final product. The set of parameters and levels is determined by an orthogonal array (OA) to evaluate the characteristic quality through a minimal number of experiments [49]. The OA is determined by the number of factors and levels. The total degree of freedom (DoF) is used to calculate the minimum required orthogonal array for the optimisation analysis $[49,50]$. In this study, the cutting force, cutting power and the chip-tool interface temperature was optimised for a given set of factors: cutting speed $(\mathrm{m} / \mathrm{min})$, depth of cut $(\mathrm{mm})$ and feed rate $(\mathrm{mm} / \mathrm{rev})$. Four different levels and the three factors were used, as shown in Table 3. Taguchi orthogonal array $\left(\mathrm{L}_{16}\right)$ of 16 sets of simulations are as shown in Table 4. The MINITAB 17 statistical software was used for Taguchi design of experiment and analysis of the finite element simulated data.

\section{Results}

\subsection{Validation of the DEFORM 3D turning simulations}

It is important to validate the results obtained from finite element simulations using experimental data as established
Table 4. $\mathrm{L}_{16}$ orthogonal design array.

\begin{tabular}{llll}
\hline Trial no. & \multicolumn{3}{c}{ Simulation control factors } \\
\cline { 2 - 4 } & $\begin{array}{l}\text { Cutting } \\
\text { speed } \\
(\mathrm{m} / \mathrm{min})\end{array}$ & $\begin{array}{l}\text { Depth } \\
\text { of cut } \\
(\mathrm{mm})\end{array}$ & $\begin{array}{l}\text { Feed rate } \\
(\mathrm{mm} / \mathrm{rev})\end{array}$ \\
\hline 1 & 30 & 0.25 & 0.10 \\
2 & 30 & 0.75 & 0.15 \\
3 & 30 & 1.00 & 0.25 \\
4 & 30 & 2.00 & 0.30 \\
5 & 60 & 0.25 & 0.15 \\
6 & 60 & 0.75 & 0.10 \\
7 & 60 & 1.00 & 0.3 \\
8 & 60 & 2.00 & 0.25 \\
9 & 120 & 0.25 & 0.25 \\
10 & 120 & 0.75 & 0.30 \\
11 & 120 & 1.00 & 0.10 \\
12 & 120 & 2.00 & 0.15 \\
13 & 150 & 0.25 & 0.30 \\
14 & 150 & 0.75 & 0.25 \\
15 & 150 & 1.00 & 0.15 \\
16 & 150 & 2.00 & 0.10 \\
\hline
\end{tabular}

in previous works $[37,47,51,52]$. In this study, the cutting forces obtained from the DEFORM simulation were validated using experimental data presented by Genga et al. [45]. A similar approach has been used by other authors [33,53].

Table 5 shows the comparison between cutting forces obtained from simulation and experimental results. The cutting force obtained from the DEFORM ${ }^{\circledR} 3 \mathrm{D}$ software exhibited a similar trend to the experimental data of Genga et al. [17]. However, there were deviations between the predicted and the experiment cutting force. These deviations are often expected and are due to the simplification of the finite element model, which does not adequately consider all factors influencing the machining process [33]. Since the cutting force values are somewhat close, the DEFORM simulation was used to predict machining responses for the entire test conditions listed in Table 4. These responses were then used for completing Taguchi, ANOVA and regression analyses to determine the optimum turning parameters. Furthermore, the optimum turning parameters were then fed back into DEFORM software for confirmatory simulations.

\subsection{Taguchi's experimental design}

Machining processes are affected by several factors some of which include cutting speed, feed rate, depth of cut, tool geometry, temperature, cutting fluid types, mode of cutting fluid delivery, material types and materials properties [20]. These parameters exhibit complex interrelationships which influence several machining responses such as those considered in this study - cutting forces, 
Table 5. Comparison of simulation and experimental cutting force results of Ti-6Al-4V alloy.

\begin{tabular}{|c|c|c|c|c|c|c|}
\hline \multirow[t]{2}{*}{ Test conditions } & \multicolumn{3}{|c|}{ Numerical directional/plane forces } & \multicolumn{2}{|c|}{ Resultant forces } & \multirow[t]{2}{*}{ Deviation } \\
\hline & $\mathrm{F}_{\mathrm{x}}$ & $\mathrm{F}_{\mathrm{y}}$ & $\mathrm{F}_{\mathrm{z}}$ & $\mathrm{F}_{\mathrm{r}}$ (simulation) & Fr (experimental) & \\
\hline $\begin{array}{l}\text { Cutting speed }(45 \mathrm{~m} / \mathrm{min}) \\
\text { Depth of cut }(2.0 \mathrm{~mm}) \\
\text { Feed rate }(0.2 \mathrm{~mm} / \mathrm{ref})\end{array}$ & 246.83 & 1196.25 & 219.32 & 1240.99 & 1081.99 & $+15 \%$ \\
\hline $\begin{array}{l}\text { Cutting speed }(60 \mathrm{~m} / \mathrm{min}) \\
\text { Depth of cut }(2.0 \mathrm{~mm}) \\
\text { Feed rate }(0.2 \mathrm{~mm} / \mathrm{ref})\end{array}$ & 739.50 & 1250.22 & 268.32 & 1477.12 & 1483.52 & $-0.5 \%$ \\
\hline $\begin{array}{l}\text { Cutting speed }(120 \mathrm{~m} / \mathrm{min}) \\
\text { Depth of cut }(0.25 \mathrm{~mm}) \\
\text { Feed rate }(0.15 \mathrm{~mm} / \mathrm{ref})\end{array}$ & 5.72 & 101.00 & 23.08 & 103.76 & 86.4 & $+20 \%$ \\
\hline
\end{tabular}

Table 6. Simulation results of cutting force $(\mathrm{N})$, temperature $\left({ }^{\circ} \mathrm{C}\right)$ and cutting power $(\mathrm{kW})$.

\begin{tabular}{lllllllrl}
\hline $\begin{array}{l}\text { Cutting } \\
\text { speed } \\
(\mathrm{m} / \mathrm{min})\end{array}$ & $\begin{array}{l}\text { Depth } \\
\text { of cut } \\
(\mathrm{mm})\end{array}$ & $\begin{array}{l}\text { Feed } \\
\text { rate } \\
(\mathrm{mm} / \mathrm{ref})\end{array}$ & $\begin{array}{l}\text { Cutting } \\
\text { force } \\
(\mathrm{N})\end{array}$ & $\begin{array}{l}\text { Cutting } \\
\text { Power } \\
(\mathrm{kW})\end{array}$ & $\begin{array}{l}\text { Chip-tool } \\
\text { temperature } \\
\left({ }^{\circ} \mathrm{C}\right)\end{array}$ & $\begin{array}{l}\text { S/N ratio } \\
\text { for cutting } \\
\text { force }\end{array}$ & $\begin{array}{l}\text { S/N ratio } \\
\text { for cutting } \\
\text { power }\end{array}$ & $\begin{array}{l}\text { S/N ratio } \\
\text { for chip-tool } \\
\text { temperature }\end{array}$ \\
\hline 30 & 0.25 & 0.10 & 104.78 & 0.05 & 674.50 & -40.41 & 26.02 & -56.58 \\
30 & 0.75 & 0.15 & 563.48 & 0.28 & 731.90 & -55.02 & 11.06 & -57.29 \\
30 & 1.00 & 0.25 & 1033.54 & 0.51 & 763.40 & -60.29 & 5.85 & -57.66 \\
30 & 2.00 & 0.30 & 2090.07 & 1.05 & 744.60 & -66.40 & -0.42 & -57.44 \\
60 & 0.25 & 0.15 & 148.35 & 0.15 & 600.30 & -43.43 & 16.48 & -55.57 \\
60 & 0.75 & 0.10 & 582.41 & 0.58 & 817.90 & -55.30 & 4.73 & -58.25 \\
60 & 1.00 & 0.30 & 1058.75 & 1.05 & 863.80 & -60.50 & -0.42 & -58.73 \\
60 & 2.00 & 0.25 & 1747.99 & 1.77 & 817.50 & -64.85 & -4.96 & -58.25 \\
120 & 0.25 & 0.25 & 142.42 & 0.28 & 954.90 & -43.07 & 11.06 & -59.60 \\
120 & 0.75 & 0.30 & 752.26 & 1.49 & 881.00 & -57.53 & -3.46 & -58.90 \\
120 & 1.00 & 0.10 & 543.06 & 1.08 & 993.00 & -54.70 & -0.67 & -59.94 \\
120 & 2.00 & 0.15 & 1384.21 & 2.80 & 996.40 & -62.82 & -8.94 & -59.97 \\
150 & 0.25 & 0.30 & 178.16 & 0.44 & 891.80 & -45.02 & 7.13 & -59.01 \\
150 & 0.75 & 0.25 & 615.79 & 1.53 & 985.30 & -55.79 & -3.69 & -59.87 \\
150 & 1.00 & 0.15 & 766.44 & 1.91 & 1018.20 & -57.69 & -5.62 & -60.16 \\
150 & 2.00 & 0.10 & 1060.28 & 2.68 & 1000.70 & -60.51 & -8.56 & -60.01 \\
& & & Total mean & & -55.21 & 2.85 & -58.58 \\
\hline
\end{tabular}

cutting power and chip-tool interface temperature. Therefore, it is important to optimise machining process parameters to identify the most significant parameter influencing a particular machining operation.

In this study, Taguchi optimisation was done by taking cutting speed, depth of cut, and feed rate as independent turning parameters while cutting force, chip-tool interface temperature and cutting power were taken as the response factors. Table 6 shows the Taguchi's factor-response for the numerical modelling as per the OA described in Section 2.2. The signal-to-noise $(\mathrm{S} / \mathrm{N})$ ratio quality characteristics for the responses are shown, and according to this methodology, the highest value of $\mathrm{S} / \mathrm{N}$ ratio represents a better quality. For all the responses, the objective was to minimise their effects, and therefore the criterion of 'smaller-thebetter' was adopted [28].

\subsubsection{Cutting force}

Table 7 shows the $\mathrm{S} / \mathrm{N}$ response for the cutting force and the corresponding means of $\mathrm{S} / \mathrm{N}$ ratios for the three parameters are as shown in Figure 3. The objective of every machining process is to minimise the resultant cutting forces, and therefore, Taguchi single objective is to minimise the response output in this case. As shown, the highest $\mathrm{S} / \mathrm{N}$ ratios were obtained at level 3 for cutting speed, and level 1 for both depth of cut and feed rate. This result means that the optimal conditions for minimising cutting force were cutting speed, depth of cut and feed rate of $120 \mathrm{~mm} / \mathrm{s}, \quad 0.25 \mathrm{~mm}$ and $0.1 \mathrm{~mm} / \mathrm{rev}$ respectively. Furthermore, as shown in Table 7 , the depth of cut exhibited the highest delta value and indicates that it is the most significant parameter influencing the cutting force in 
Table 7. S/N response table for cutting force.

\begin{tabular}{lllll}
\hline Level & Cutting speed $(\mathrm{m} / \mathrm{min})$ & Depth of cut $(\mathrm{mm})$ & Feed rate $(\mathrm{mm} / \mathrm{rev})$ & Mean S/N ratio \\
\hline 1 & -55.53 & $-\mathbf{4 2 . 9 8}$ & $-\mathbf{5 2 . 7 3}$ & -50.41 \\
2 & -56.02 & -55.91 & -54.74 & -55.56 \\
3 & $\mathbf{- 5 4 . 5 3}$ & -58.29 & -56.00 & -56.27 \\
4 & -54.75 & -63.65 & -57.36 & -58.59 \\
Delta & 1.49 & 20.67 & 4.63 & \\
Rank & 3 & 1 & 2 & \\
\hline
\end{tabular}

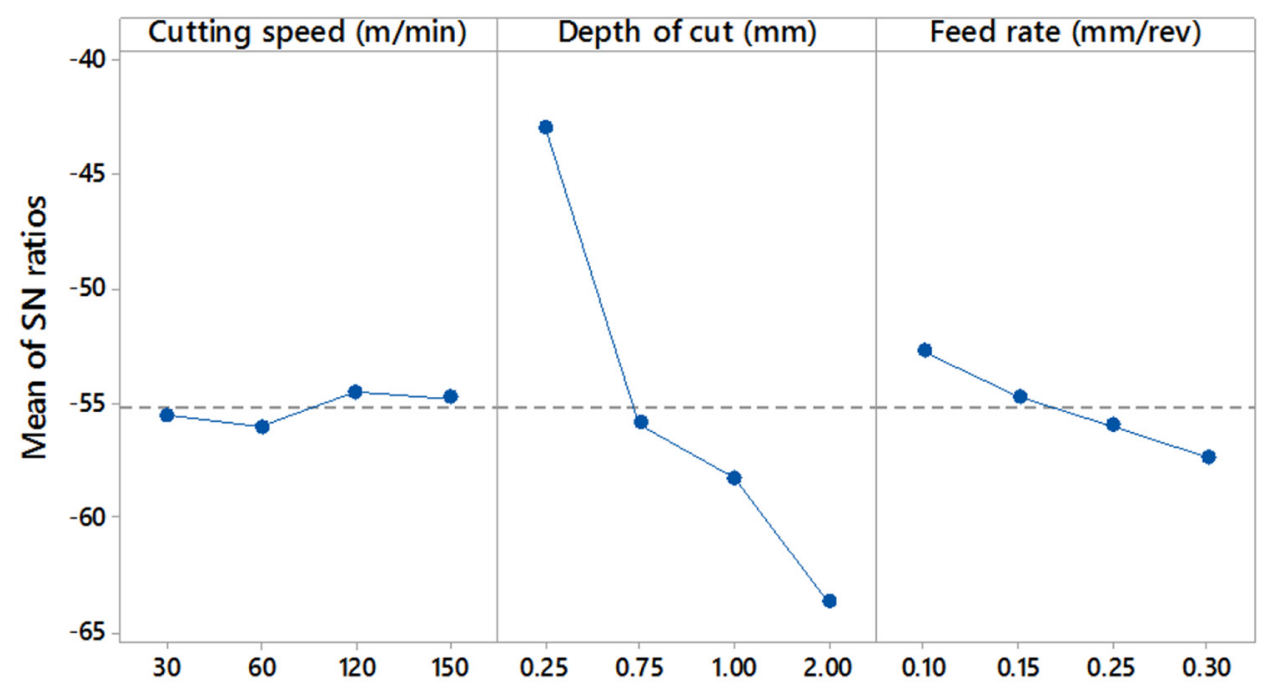

Signal-to-noise: Smaller is better

Fig. 3. Main effects plot of $\mathrm{S} / \mathrm{N}$ ratios of cutting force during turning simulation.

a turning operation. However, cutting speed influenced cutting force the least.

\subsubsection{Cutting power}

The $\mathrm{S} / \mathrm{N}$ responses for the individual factors for the cutting power response are as shown in both Figure 4 and Table 8. The optimum cutting power occurred at level 1 of all the cutting factors. This result means that to obtain the minimum cutting power during the machining of the Ti-6Al-4V alloy cutting speed of $30 \mathrm{~mm} / \mathrm{s}$, depth of cut of $0.25 \mathrm{~mm}$ and feed rate of $0.1 \mathrm{~mm} / \mathrm{rev}$. As shown, the depth of cut is the most significant factor followed by cutting speed while the feed rate is the most insignificant factor influencing the cutting power during the turning operation.

\subsubsection{Chip-tool interface temperature}

The $\mathrm{S} / \mathrm{N}$ response table and plots of means for the influence of each parameter to the interface temperature are as given in Figure 5 and Table 9 . In this case, the optimum set point for this response was at level 1 for cutting speed and depth of cut and level 2 for feed rate. This result indicates that the optimum conditions for minimizing chip-tool interface temperature is favourable at $30 \mathrm{~mm} / \mathrm{s}, 0.25 \mathrm{~mm}$ and $0.75 \mathrm{~mm} / \mathrm{rev}$ for cutting speed, depth of cut and feed rate respectively. The cutting speed is the most significant parameter influencing chip-tool interface temperature, whereas the feed rate has the lowest influence on the contact temperature.

\subsection{Analysis of variance and regression}

The effects of the machining parameters on the turning process of the Ti-6Al-4V were further analysed through Analysis of Variance (ANOVA), and the results are as shown in Table 10. The ANOVA analysis provides a procedure of testing the statistical hypothesis of occurrences of multivariate data. In this analysis, $P$-value is an important parameter as it shows the significance of the factors to the responses. Additionally, F-value evaluates the null hypothesis of the study; in this case, the null hypothesis is that cutting speed, depth of cut and feed rate does not affect the machining responses. As shown for the cutting force response, all the factors, except cutting speed have $\mathrm{P}$-values less than 0.05 indicating their significance. The depth of cut has the highest significance and contributes about $84 \%$ to the cutting force, whereas the 


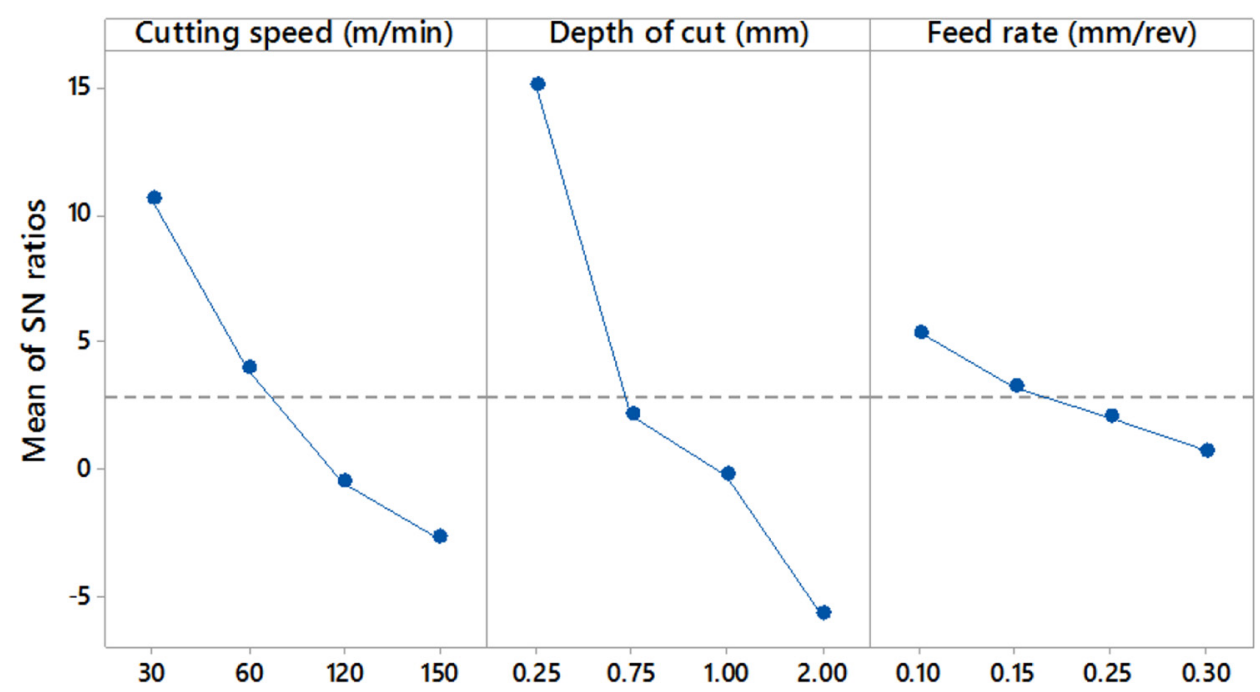

Signal-to-noise: Smaller is better

Fig. 4. Main effects plot of $\mathrm{S} / \mathrm{N}$ ratios of cutting power during turning simulation.

Table 8. S/N response table for cutting power.

\begin{tabular}{lcclc}
\hline Level & Cutting speed $(\mathrm{m} / \mathrm{min})$ & Depth of cut $(\mathrm{mm})$ & Feed rate $(\mathrm{mm} / \mathrm{rev})$ & Mean S/N ratio \\
\hline 1 & $\mathbf{1 0 . 6 3}$ & $\mathbf{1 5 . 1 7}$ & $\mathbf{5 . 3 8}$ & 10.39 \\
2 & 3.96 & 2.16 & 3.24 & 3.12 \\
3 & -0.5 & -0.22 & 2.06 & 0.45 \\
4 & -2.69 & -5.72 & 0.7 & -2.57 \\
Delta & 13.31 & 20.89 & 4.68 & \\
Rank & 2 & 1 & 3 & \\
\hline
\end{tabular}

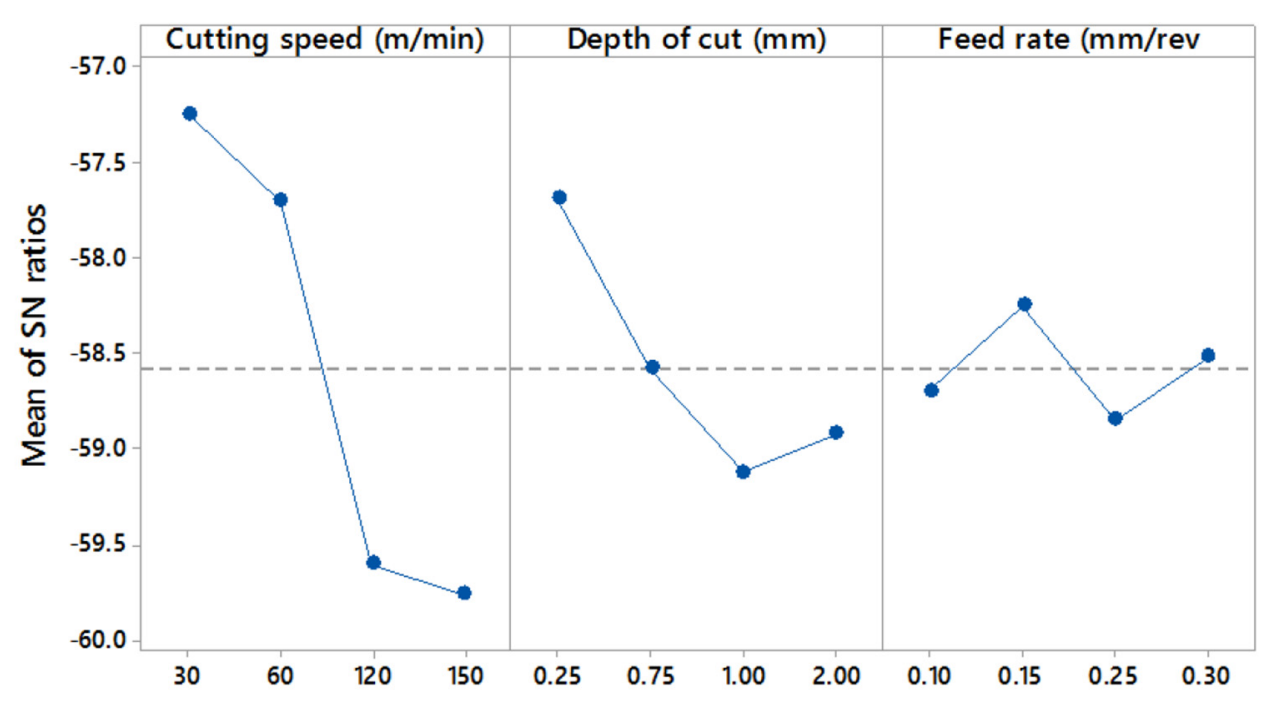

Signal-to-noise: Smaller is better

Fig. 5. Main effects plot of $\mathrm{S} / \mathrm{N}$ ratios of chip-tool interface temperature during turning simulation. 
Table 9. S/N response table for chip-tool interface temperature.

\begin{tabular}{lllll}
\hline Level & Cutting speed $(\mathrm{m} / \mathrm{min})$ & Depth of cut $(\mathrm{mm})$ & Feed rate $(\mathrm{mm} / \mathrm{rev})$ & Mean S/N ratio \\
\hline 1 & $\mathbf{5 7 . 2 4}$ & $-\mathbf{5 7 . 6 9}$ & -58.69 & -57.87 \\
2 & -57.7 & -58.58 & $-\mathbf{5 8 . 2 5}$ & -58.18 \\
3 & -59.6 & -59.12 & -58.84 & -59.19 \\
4 & -59.76 & -58.92 & -58.52 & -59.07 \\
Delta & 2.52 & 1.43 & 0.6 & \\
Rank & 1 & 2 & 3 & \\
\hline
\end{tabular}

Table 10. Results of ANOVA for cutting force, temperature and power.

\begin{tabular}{lllllll}
\hline Factor & DoF & Adj SS & Adj MS & F-Value & P-Value & Contribution $(\%)$ \\
\hline Cutting force & & & & & & \\
Cutting speed (m/min) & 3 & 235641 & 78547 & 4.42 & 0.058 & 4.69 \\
Depth of cut (mm) & 3 & 4227679 & 1409226 & 79.38 & 0.000 & $\mathbf{8 4 . 1 0}$ \\
Feed rate (mm/rev) & 3 & 457336 & 152445 & 8.59 & 0.014 & 9.10 \\
Error & 6 & 106519 & 17753 & & & 2.12 \\
Total & 15 & 5027175 & & & 100.00 \\
Temperature & & & & & \\
Cutting speed (m/min) & 3 & 187108 & 62369 & 18.16 & 0.002 & $\mathbf{7 4 . 3 3}$ \\
Depth of cut (mm) & 3 & 38858 & 12953 & 3.77 & 0.078 & 15.44 \\
Feed rate (mm/rev) & 3 & 5173 & 1724 & 0.50 & 0.695 & 2.05 \\
Error & 6 & 20604 & 3434 & & & 8.18 \\
Total & 15 & 251743 & & & 100.00 \\
Power & & & & & \\
Cutting speed (m/min) & 3 & 3.3125 & 1.10417 & 8.01 & 0.016 & 29.48 \\
Depth of cut (mm) & 3 & 6.9032 & 2.30106 & 16.70 & 0.003 & $\mathbf{6 1 . 4 3}$ \\
Feed rate (mm/rev) & 3 & 0.1950 & 0.06501 & 0.47 & 0.713 & 1.74 \\
Error & 6 & 0.8268 & 0.13781 & & & 7.36 \\
Total & 15 & 11.2375 & & & & 100.00 \\
\hline
\end{tabular}

cutting speed has the lowest influence on the cutting force, with a contribution of $\sim 4.7 \%$. The F-values are all away from unity (1) indicating that the null hypothesis can be rejected. Therefore, rejecting the null hypothesis means that the three factors affect the turning operation of the titanium alloy. Even the most insignificant factor (cutting speed) has a $\mathrm{P}$-value, which is not very far from 0.05 .

Similar analysis was performed on chip-tool interface temperature and cutting power. The results showed that the cutting speed was the only parameter whose P-value was less than 0.05 for chip-tool interface temperature response. It's contribution to chip-tool interface temperature was estimated at $74.33 \%$. The feed rate has a very high value of $\mathrm{P}(0.695)$ which indicates its insignificance to the chip-tool interface temperature. A close look of the F-values for the factors under temperature response shows that cutting speed and depth of cut have values far away from unity (1) while the feed rate has an F-value of 0.5 , which is closer to one. These analyses imply that the null hypothesis cannot be rejected based on the three factors but the first two factors only. Similar results can be seen on for the F-values under the cutting power. However, it can be seen that the depth of cut has the most significant influence on the cutting power with the highest contribution of $61.4 \%$. The feed rate has the lowest influence on the cutting power with an overall contribution of $1.74 \%$. The results obtained from ANOVA corroborate the most significant parameters indicated by the delta values obtained from optimisation of Taguchi response in Section 3.1.

To understand the relationship between dependent and independent variables in this study, regression analyses were undertaken with cutting force $(\mathbf{F})$, chip-tool interface temperature ( $\mathbf{T})$ and cutting power $(\mathbf{P})$ as the dependent factors whereas the independent factors were cutting speed $\left(\mathbf{C}_{\mathbf{s}}\right)$, feed rate $\left(\mathbf{f}_{\mathbf{r}}\right)$, and depth of cutting $\left(\mathbf{d}_{\mathbf{c}}\right)$. The predictive equations based on the linear regression analysis 


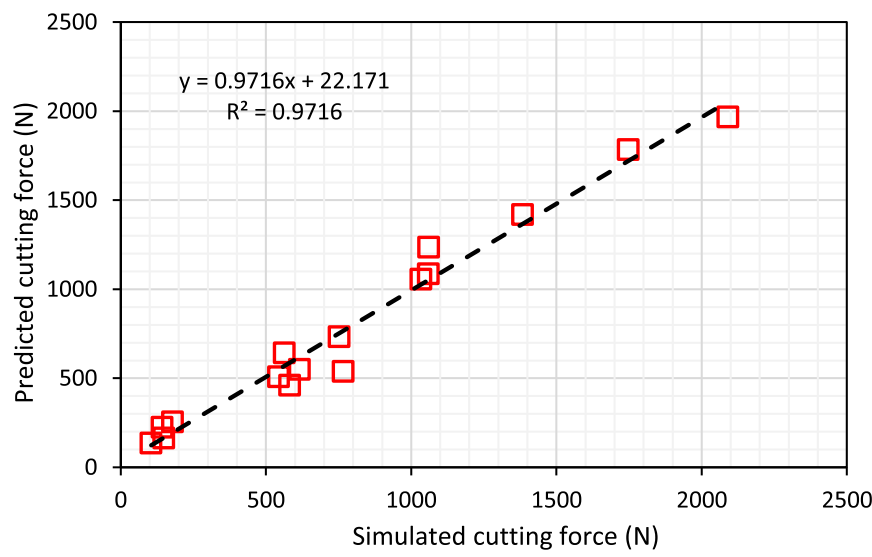

(a)

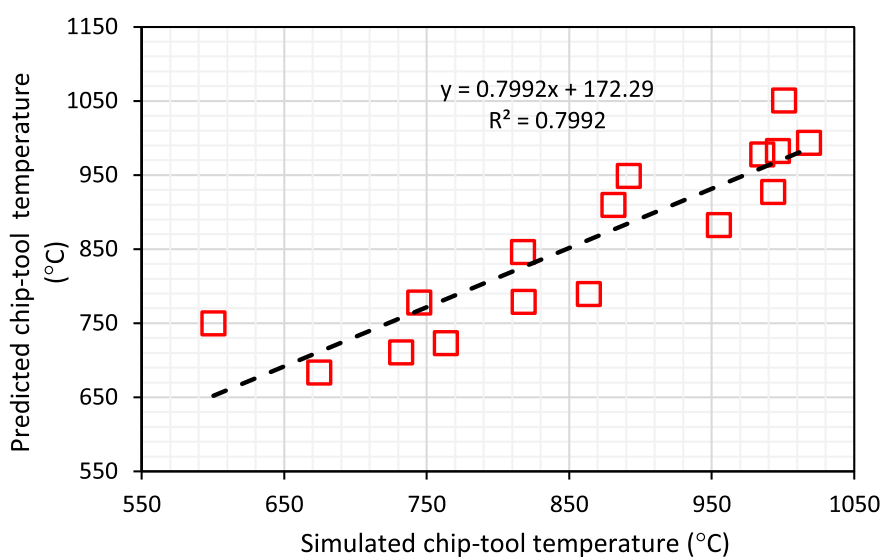

(b)

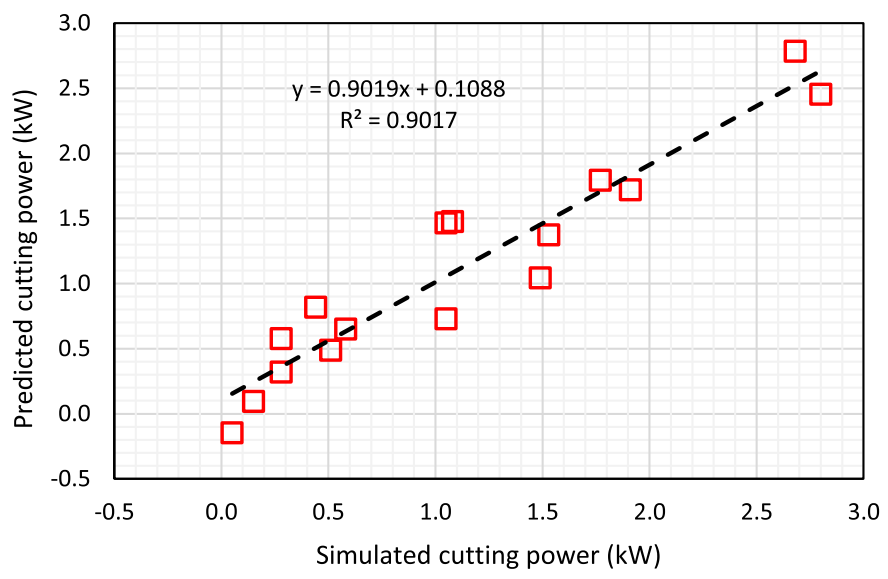

(c)

Fig. 6. A plot comparing the response factor obtained by the regression model. (a) Comparison of the predicted and simulated cutting force. (b) Comparison of the predicted and simulated chip-tool temperature. (c) Comparison of predicted and simulated cutting power.

for the dependent factors are represented below.

$$
\begin{gathered}
F=-202-2.548 C_{s}+803.7 d_{c}+2127 f_{r} \quad\left(R^{2}=0.97\right) \\
T=604.3+2.241 C_{s}+56.0 d_{c}-18 f_{r} \quad\left(R^{2}=0.80\right)
\end{gathered}
$$$$
P=-0.599+0.00953 C_{s}+1.022 d_{c}+0.885 f_{r} \quad\left(R^{2}=0.90\right)
$$

Plots comparing the predicted and simulated values of the cutting force, temperature and cutting power are as shown in Figure 6. The $R^{2}$ values for each of the regression are computed and indicated in the regression equations above. The results showed that the $R^{2}$ values are closer to 1 , indicating that the equations obtained from the linear regression can estimate the cutting force, chip-tool interface temperature and cutting power.

\subsection{Confirmation simulation}

From the Taguchi design of experimental trials, the optimal parameters (cutting speed, depth of cut, and feed rate) for turning of Ti-6Al-4V alloy considering three machining response (cutting force, cutting power and chiptool interface temperature) were determined. These optimal parameters variables are as summarised in Table 11. The parameters were used to run confirmatory turning simulations on the DEFORM software, the measured cutting force, cutting power, and chip-tool temperature are as shown in Table 11. The results show that the optimisation of turning parameters considering cutting force as the response resulted in the lowest cutting force $(88.21 \mathrm{~N})$ and chip-tool temperature $\left(387.24^{\circ} \mathrm{C}\right)$. Chip-tool interface temperature was next to cutting force response while cutting power response was the highest. This results indicate that optimising turning parameters (cutting speed, depth of cut, and feed rate) with cutting force response as the target is more effective than the other machining responses [54].

\section{Discussion}

Reducing the cost of machining during manufacturing of titanium-based product is a long-coveted desire. However, 
Table 11. Summarised optimal parameters and output of the confirmation simulation.

\begin{tabular}{|c|c|c|c|c|}
\hline \multirow[b]{2}{*}{ Responses } & \multirow[b]{2}{*}{ Optimal test conditions } & \multicolumn{3}{|c|}{ Optimal simulation results } \\
\hline & & Cutting force $(\mathrm{N})$ & Cutting power $(\mathrm{kW})$ & Temperature $(\mathrm{C})$ \\
\hline Cutting Force $(\mathrm{N})$ & $\begin{array}{l}\text { Cutting speed }(120 \mathrm{~m} / \mathrm{min}) \\
\text { Depth of cut }(0.25 \mathrm{~mm}) \\
\text { Feed rate }(0.1 \mathrm{~mm} / \mathrm{rev})\end{array}$ & 88.21 & 0.17 & 387.24 \\
\hline Cutting power $(\mathrm{kW})$ & $\begin{array}{l}\text { Cutting speed }(30 \mathrm{~m} / \mathrm{min}) \\
\text { Depth of cut }(0.25 \mathrm{~mm}) \\
\text { Feed rate }(0.1 \mathrm{~mm} / \mathrm{rev})\end{array}$ & 137.19 & 0.07 & 689.88 \\
\hline Chip-tool Temperature $\left({ }^{\circ} \mathrm{C}\right)$ & $\begin{array}{l}\text { Cutting speed }(30 \mathrm{~m} / \mathrm{min}) \\
\text { Depth of cut }(0.25 \mathrm{~mm}) \\
\text { Feed rate }(0.15 \mathrm{~mm} / \mathrm{rev})\end{array}$ & 116.48 & 0.06 & 494.63 \\
\hline
\end{tabular}

high cost of experiment and difficulty associated with achieving good machinability in titanium alloys have remained an impediment. Computational methods involving finite element modelling coupled with Taguchi experimental design and statistical analysis [55-57] could be used to reduce the cost of conducting machining experiments. Lower production cost can be achieved by determining optimum parameters for obtaining good machinability. The typical machinability indicators include surface roughness of the workpiece, metal removal rate and tool wear rate [58]. These indicators largely influence the cutting forces, chip-tool interface temperature, chip formation, cutting power and residual stress which are machining responses taken during experiments [57]. Of these responses, this study focused on the cutting forces, cutting power and chip-tool interface temperatures which promote tool wear and surface roughness of the workpiece when their values are high. You et al. [46] confirmed from experimental analyses that lower feed rate, slow cutting speed and small depth of cut offered significant advantage in minimising surface roughness and tool wear rate during turning operation. This study focused on minimising the cutting force, cutting power and chip-tool interface temperature during turning of Ti- $6 \mathrm{Al}-4 \mathrm{~V}$ alloy. This was achieved by considering two important research questions:

- Could DEFORM simulation be used to predict the machining response of Ti- $6 \mathrm{Al}-4 \mathrm{~V}$ during turning operation?

- What are the preferred or most significant conditions for reducing machining response during turning of Ti-6Al-4V?

These questions are addressed in two parts. In the first part of this study, DEFORM simulation results were compared with experimental results (Tab. 5). The results showed that the cutting force obtained from predictions follow a similar trend as the experiment, but there were up to $20 \%$ deviations in the cutting forces. These deviations are expected because experimental conditions are rarely truly represented in simulations, assumptions have to be made during simulations to simplify the model. One assumption made during the simulations in this study is that a constant coefficient of friction was taken to be 0.6 to represent a wet machining carried out by Genga et al. [45]. During turning experiment, the coefficient of friction may not be constant, and this may explain the slight discrepancies in the values of the cutting forces obtained during simulations and experiments. Li and Shih [33] and Vosough et al. [53] have both reported variations of up to $15 \%$ when cutting forces optioned from experiment and simulations were compared. Despite the discrepancies observed in this study, the authors considered the machining response obtained from the DEFORM simulations to be valid since the trends are similar.

In the second part, Taguchi, ANOVA and regression analyses were used to determine the optimum parameters for minimising the machining response. The results presented in Sections 3.2.1-3.2.3 indicated that $120 \mathrm{~m} /$ min, $0.25 \mathrm{~mm}$, and $0.1 \mathrm{~mm} / \mathrm{rev}$ are the optimum parameters for minimising cutting force response, $30 \mathrm{~m} / \mathrm{min}$, $0.25 \mathrm{~mm}$, and $0.1 \mathrm{~mm} / \mathrm{rev}$ are the optimum parameters for cutting power response and $30 \mathrm{~m} / \mathrm{min}, 0.25 \mathrm{~mm}$ and $0.1 \mathrm{~mm} / \mathrm{rev}$ are the optimum parameters for chip-tool interface temperature response. For every response, the parameter with the most significant influence was determined using Taguchi and ANOVA. The observations from the two analyses were consistent; depth of cut has the largest contribution to cutting force and cutting power while cutting speed has the largest contribution to chiptool interface temperature. These observations are also in agreement with some experimental findings of previous authors. Abhang and Hameedullah [59], Kamruzzaman et al. [60] and Heigel et al. [61] reported that increasing cutting speed had the most significant influence on the chip-tool interface temperature. High cutting speed increases the friction at the tool-workpiece interface. Due to the low thermal conductivity of titanium alloys, the workpiece heats up. During machining, there is no sufficient time for heat dissipation into the environment to occur, hence interface temperature increases. Experimental findings on the effect of cutting parameters on cutting force have been inconsistent. Kosaraju et al. [62] deduced from Taguchi analysis that cutting speed had the highest effect on cutting force when compared with feed rate and depth of cut. This finding is inconsistent with the observation from this work. The contradiction was due to the small experimental matrix: 
lower cutting speed $(45-75 \mathrm{~m} / \mathrm{min})$, and depth of cuts $\left(0.5^{-}\right.$ $1.5 \mathrm{~mm}$ ) considered in their work. In another study, Andriya and Narashimhulu [63] reported that the main factor which influences cutting forces during dry machining of $\mathrm{Ti}-6 \mathrm{Al}-4 \mathrm{~V}$ is the depth of cut, this observation is consistent with the prediction in this study, however, the turning simulation condition were different. It appears that determining the parameter with the largest contribution to cutting force during turning operation is highly dependent on the experimental matrix. Therefore, it is proposed that subsequent studies on turning of titanium alloys should consider correlating findings from different experimental matrix with simulations to validate the critical parameters driving machining responses.

Amongst the three machining responses considered in this study, regression analysis (Fig. 6) showed that cutting force response had the highest correlation coefficient with the cutting parameters. The confirmatory turning simulation on DEFORM also indicated that using optimised parameters, cutting force response could significantly minimise all the machining responses considered in this study. From the simulation results, it shows that other machining responses such as surface roughness, and tool wear rate can be minimised by optimising the cutting force and chip-tool interface temperature.

\section{Conclusion}

In this work, turning simulation on DEFORM, Taguchi method and ANOVA were used to analyse turning operation of Ti-6Al-4V alloy. From the results, the following conclusions can be drawn:

- DEFORM 3D turning simulation can be used to obtain machining responses that are close to experimental outcomes for machining Ti-6Al-4V alloy. This would reduce the cost of machining experiment significantly.

- Taguchi analysis and ANOVA showed that optimum parameters for cutting force response (cutting speed of $120 \mathrm{~m} / \mathrm{min}, 0.25 \mathrm{~mm}$ depth of cut and $0.1 \mathrm{~mm} / \mathrm{rev}$ ) were most effective in minimising cutting force, cutting power and chip-tool interface temperatures. These parameters would offer the best machinability during turning of Ti-6Al-4V alloy.

- In this study, cutting speed was identified as a critical parameter that influenced tool-workpiece interface temperature, and this was consistent with the findings of previous authors. However, depth of cut which was identified as the critical parameter that influence cutting forces in this study differs from the work of previous authors. This was attributed to the variations in experimental design as well as the wide range of parameters considered in different studies on machining of titanium alloys.

- It is recommended that a range of standardised parameters for different titanium machining processes should be established not only to compare results obtained by different researchers but also to accurately capture the progress and recent advances in the machining of titanium alloys.
- The experimental validation of the expanded parameters in this study is currently being considered as part of our future work on machining of $\mathrm{Ti}-6 \mathrm{Al}-4 \mathrm{~V}$ and other experimental titanium alloys.

This work was supported through the AESA-RISE Fellowship Programme [ARPDF 18-03], AESA-RISE is an independent funding scheme of the African Academy of Sciences (AAS) implemented with the support of Carnegie Corporation of New York. At The AAS, AESA-RISE is implemented through AESA, the Academy's agenda and programmatic platform, created in collaboration with the African Union Development Agency (AUDA-NEPAD). The views expressed in this publication are those of the author(s) and not necessarily those of the AAS, AUDA-NEPAD or Carnegie Corporation.

\section{References}

1. R.R. Boyer, Titanium and its alloys: metallurgy, heat treatment and alloy characteristics. In: Encyclopedia of Aerospace Engineering, American Cancer Society, 2010

2. M. Jackson, R.R. Boyer, Titanium and its alloys: processing, fabrication and mechanical performance. In: Encyclopedia of Aerospace Engineering, John Wiley \& Sons, Ltd (2010)

3. R.R. Boyer, Attributes, characteristics, and applications of titanium and its alloys, JOM 62 (2010) 21-24

4. G. Lütjering, J.C. Williams, Engineering Materials: Titanium, Second, Springer, Berlin Heidelberg Newyork, 2007

5. M.J. Donachie, Titanium: A Technical Guide, 2nd Edition. ASM International, 2000

6. C. Leyens, M. Peters, Titanium and titanium alloys: fundamentals and application, WILEY-VCH, Germany, 2003

7. M.O. Bodunrin, L.H. Chown, J.A. Omotoyinbo, Development of low-cost titanium alloys: a chronicle of challenges and opportunities, Mater. Today Proc. (2020) https://doi. org/10.1016/j.matpr.2020.02.978

8. M.O. Bodunrin, K.K. Alaneme, L.H. Chown, Aluminium matrix hybrid composites: a review of reinforcement philosophies; mechanical, corrosion and tribological characteristics, J. Mater. Res. Technol. 4 (2015) 434-445

9. F.H. (Sam) Froes, H. Friedrich, J. Kiese, D. Bergoint, Titanium in the family automobile: the cost challenge, JOM 56 (2004) 40-44.

10. M.O. Bodunrin, L.H. Chown, J.W. van der Merwe, K.K. Alaneme, On the substitution of vanadium with iron in Ti-6Al-4V: thermo-calc simulation and processing map considerations for design of low-cost alloys, Mater. Sci. Eng. A 791 (2020) 139622.

11. SAmaterials (2014) Why Titanium is So Expensive. In: Stanford Advanced Materials. https://samaterials.wordpress.com/2014/ 07/29/why-titanium-is-so-expensive/ (accessed 22 October 2016)

12. A. Pramanik, Problems and solutions in machining of titanium alloys, Int. J. Adv. Manuf. Technol. 70 (2014) 919-928

13. L. Bolzoni, E.M. Ruiz-Navas, E. Gordo, Understanding the properties of low-cost iron-containing powder metallurgy titanium alloys, Mater. Des. 110 (2016) 317-323

14. P.G. Esteban, E.M. Ruiz-Navas, L. Bolzoni, E. Gordo, Low-cost titanium alloys? Iron may hold the answers, Metal Powder Report 63 (2008) 24-27 
15. N.S. Weston, M. Jackson, FAST-forge - a new cost-effective hybrid processing route for consolidating titanium powder into near net shape forged components, J. Mater. Process. Technol. 243 (2017) 335-346

16. N.S. Weston, M. Jackson, FAST-forge of titanium alloy swarf: a solid-state closed-loop recycling approach for aerospace machining waste, Metals 10 (2020) 296

17. K.-H. Park, M.A. Suhaimi, G.-D. Yang et al., Milling of titanium alloy with cryogenic cooling and minimum quantity lubrication (MQL), Int. J. Precis. Eng. Manuf. 18 (2017) $5-14$

18. R.S. Revuru, J.Z. Zhang, N.R. Posinasetti, T. Kidd, Optimization of titanium alloys turning operation in varied cutting fluid conditions with multiple machining performance characteristics, Int. J. Adv. Manuf. Technol. 95 (2018) 1451-1463

19. R.S. Revuru, N.R. Posinasetti, V.R. Vsn, M. Amrita, Application of cutting fluids in machining of titanium alloys - a review, Int. J. Adv. Manuf. Technol. 91 (2017) $2477-2498$

20. J.D. Kechagias, K.-E. Aslani, N.A. Fountas et al., A comparative investigation of Taguchi and full factorial design for machinability prediction in turning of a titanium alloy, Measurement 151 (2020) 107213

21. M.O. Bodunrin, L.H. Chown, Towards the development of experimental $(\alpha+\beta)$ Ti-Al-V-Fe alloys, Mater. Today Proc. (2020) https://doi.org/10.1016/j.matpr.2020.03.645

22. S. Ganguli, S.G. Kapoor, Improving the performance of milling of titanium alloys using the atomization-based cutting fluid application system, J. Manuf. Process. 23 (2016) 29-36

23. M. Dhananchezian, M. Pradeep Kumar, Cryogenic turning of the $\mathrm{Ti}-6 \mathrm{Al}-4 \mathrm{~V}$ alloy with modified cutting tool inserts, Cryogenics 51 (2011) 34-40

24. N. Varote, S.S. Joshi, Microstructural analysis of machined surface integrity in drilling a titanium alloy, J. Mater. Eng. Perform 26 (2017) 4391-4401

25. A.D. Davydov, T.B. Kabanova, V.M. Volgin, Electrochemical machining of titanium. Review, Russ. J. Electrochem. 53 (2017) 941-965

26. J.E. Abu Qudeiri, A.-H.I. Mourad, A. Ziout et al., Electric discharge machining of titanium and its alloys: review, Int. J. Adv. Manuf. Technol. 96 (2018) 1319-1339.

27. A.K. Singh, D.P.S. Rao, A Review on Ultrasonic Machining of Titanium Alloys, International Journal of Research and Scientific Innovation (IJRSI) 5 (2018) 2321-2705

28. M. Mia, M.A. Khan, S.S. Rahman, N.R. Dhar, Mono-objective and multi-objective optimization of performance parameters in high pressure coolant assisted turning of Ti-6Al-4V, Int. J. Adv. Manuf. Technol. 90 (2017) $109-118$

29. Y. Gao, G. Wang, M.J. Bermingham, M.S. Dargusch, Cutting force, chip formation, and tool wear during the laser-assisted machining a near-alpha titanium alloy BTi-6431S, Int. J. Adv. Manuf. Technol. 79 (2015) 1949-1960

30. D. Biermann, H. Abrahams, M. Metzger, Experimental investigation of tool wear and chip formation in cryogenic machining of titanium alloys, Adv. Manuf. 3 (2015) 292-299

31. A. Jain, N. Khanna, V. Bajpai, FE simulation of machining of Ti-54M titanium alloy for industry relevant outcomes, Measurement 129 (2018) 268-276
32. M.H. Ali, M.N.M. Ansari, B.A. Khidhir et al., Simulation machining of titanium alloy (Ti-6Al-4V) based on the finite element modeling, J. Braz. Soc. Mech. Sci. Eng. 36 (2014) 315-324

33. R. Li, A.J. Shih, Finite element modeling of 3D turning of titanium, Int. J. Adv. Manuf. Technol. 29 (2006) 253-261

34. S.R. Oke, G.S. Ogunwande, M. Onifade et al., An overview of conventional and non-conventional techniques for machining of titanium alloys, Manuf. Rev. 7 (2020) 34.

35. J.O. Obiko, F.M. Mwema, M.O. Bodunrin, Finite element simulation of X20CrMoV121 steel billet forging process using the Deform 3D software, SN Appl. Sci. 1 (2019) $1-10$

36. J. Oirere, O. Fredrick, M. Mwema, H. Shangwira, Forging optimisation process using numerical simulation and Taguchi method, SN Appl. Sci. (2020) https://doi.org/10.1007/ s42452-020-2547-0

37. A. Khan, K. Maity, 3D finite element modeling for estimating key machinability aspects in turning of commercially pure titanium, Surf. Rev. Letters 26 (2019) 1-20

38. T. Tamizharasan, N. Kumar Senthil, Numerical simulation of effects of machining parameters and tool geometry using DEFORM-3D: optimization and experimental validation, World J. Model. Simul. 10 (2014) 49-59

39. M. Maarefdoust, Simulation of finite volume of hot forging process of industrial gear. 2012 International Conference on Networks and Information (ICNI 2012) 57 (2012) 111-115

40. S. Wangchaichune, S. Suranuntchai, Finite element simulation of hot forging process for KVBM gear, Appl. Mech. Mater. 875 (2018) 30-35

41. M.A.P. Juárez, E.A. Gómez, H.P. Mora et al., Finite element simulation and experimental analysis of cutting forces in orthogonal turning in AISI-1045 steel, Comput. Sist. 23 (2019) 7-20

42. R. Rajesh, J. Lilly Mercy, S. Ravikumar, A. Singh, Design and analysis of tool wear characteristics during turning using deform 3D, ARPN J. Eng. Appl. Sci. 12 (2017) 4940-4952

43. R.K. Gupta, B. Kumar, T.V.K. Gupta, D.S. Ramteke, Theoretical and experimental analysis of hard material machining, Int. J. Mech. Mechatron. Eng. 7 (2013) 2132-2138

44. B. Borsos, A. Csörgo, A. Hidas et al., Two-dimensional finite element analysis of turning processes, Period. Polytech. Mech. Eng. 61 (2017) 44-54

45. R.M. Genga, P. Zeman, J. Brajer et al., Effects of Mo2C, Ni binder and laser surface modification on WC inserts for turning Ti-6Al-4V, Int. J. Refract. Metals Hard Mater. 87 (2020) 105145

46. S.H. You, J.H. Lee, S.H. Oh, A study on cutting characteristics in turning operations of titanium alloy used in automobile, Int. J. Precis. Eng. Manuf. 20 (2019) 209-216

47. S. Kosaraju, V.G. Anne, B.B. Popuri, Finite element simulation of cutting forces in turning Ti6AI4V using deform 3D, ASME International Mechanical Engineering Congress and Exposition, Proceedings (IMECE) 2 (2013) 1-7

48. E. Kuram, Nose radius and cutting speed effects during milling of AISI 304 material, Mater. Manuf. Process. 32 (2017) 185-192

49. W. Bin Rashid, S. Goel, Parametric design optimization of hard turning of AISI 4340 steel (69 HRC), Int. J. Adv. Manuf. Technol. 82 (2016) 451-462 
50. B.K.M. Paul, T. Raju, B. Biju, Optimization of cutting parameters in hard turning of AISI 4340 steel, International Journal of Innovative Research in Advanced Engineering (IJIRAE) 1 (2014) 2349-2163

51. N. Senthilkumar, T. Tamizharasan, Effect of tool geometry in turning AISI 1045 steel: experimental investigation and FEM analysis, Arab. J. Sci. Eng. 39 (2014) 4963-4975

52. T. Özel, M. Sima, A.K. Srivastava, B. Kaftanoglu, Investigations on the effects of multi-layered coated inserts in machining Ti-6Al-4V alloy with experiments and finite element simulations, CIRP Ann.- Manuf. Technol. 59 (2010) $77-82$

53. M. Vosough, F. Schultheiss, M. Agmell, J.-E. Ståhl, A method for identification of geometrical tool changes during machining of titanium alloy Ti6Al4V, Int. J. Adv. Manuf. Technol. 67 (2013) 339-348

54. M. Lotfi, M. Jahanbakhsh, A. Akhavan Farid, Wear estimation of ceramic and coated carbide tools in turning of Inconel 625: 3D FE analysis, Tribol. Int. 99 (2016) 107-116

55. T. Tamizharasan, N. Senthilkumar, Numerical simulation of effects of machining parameters and tool geometry using DEFORM-3D: optimization and experimental validation, 13

56. T. Tamizharasan, N. Senthil Kumar, Optimization of cutting inserts geometry using DEFORM-3D: numerical simulation and experimental validation, Int. J. Simul. Model 11 (2012) $65-76$
57. A. Khan, K. Maity, 3D Finite element modeling for estimating key machinability aspects in turning of commercially pure titanium, Surf. Rev. Lett. 26 (2019) 1850136

58. N. Ahmed, S. Ahmad, S. Anwar et al., Machinability of titanium alloy through laser machining: material removal and surface roughness analysis, Int. J. Adv. Manuf. Technol. 105 (2019) 3303-3323

59. L.B. Abhang, M. Hameedullah, Chip-tool interface temperature prediction model for turning process, Int. J. Eng. Sci. Technol. 2 (2010) 12

60. M. Kamruzzaman, S.S. Rahman, Md.Z.I. Ashraf, N.R. Dhar, Modeling of chip-tool interface temperature using response surface methodology and artificial neural network in HPCassisted turning and tool life investigation, Int. J. Adv. Manuf. Technol. 90 (2017) 1547-1568

61. J.C. Heigel, E. Whitenton, B. Lane et al., Infrared measurement of the temperature at the tool-chip interface while machining Ti-6Al-4V, J. Mater. Proc. Technol. 243 (2017) 123-130

62. S. Kosaraju, V.G. Anne, B.B. Popuri, Taguchi analysis on cutting forces and temperature in turning titanium Ti-6Al-4V, 5

63. N. Andriya, M. Laeng, P. Rao, S. Ghosh, The 2012 International Conference of Manufacturing Engineering and Engineering Management, the 2012 International Conference of Mechanical Engineering. IAENG, Hong Kong, 2012

Cite this article as: Japheth O. Obiko, Fredrick M. Mwema, Michael O. Bodunrin, Validation and optimization of cutting parameters for Ti-6Al-4V turning operation using DEFORM 3D simulations and Taguchi method, Manufacturing Rev. 8, 5 (2021) 